\title{
Differences in $\mathrm{PO}_{2}$ and $\mathrm{PCO}_{2}$ between arterial and arterialized earlobe samples
}

\author{
A. Sauty, C. Uldry, L-F. Debétaz, P. Leuenberger, J-W. Fitting
}

Differences in $\mathrm{PO}_{2}$ and $\mathrm{PCO}_{2}$ between arterial and arterialized earlobe samples. A. Sauty, C. Uldry, L-F. Debétaz, P. Leuenberger, J-W. Fitting. CERS Journals Ltd 1996.

ABSTRACT: Arterialized ear lobe blood samples have been described as adequate to gauge gas exchange in acute and chronically ill patients. It is a safe procedure, usually performed by medical technicians. We have conducted a prospective study to verify the validity of this method.

One hundred and fifteen consecutive adult patients were studied. Blood samples were drawn simultaneously from arterialized earlobe and radial artery. Values of partial pressure of oxygen $\left(\mathrm{PO}_{2}\right)$ and of carbon dioxide $\left(\mathrm{PCO}_{2}\right)$ were measured by means of blood gas electrodes.

The correlation coefficients between the two samples were 0.928 for $\mathrm{PO}_{2}$ and 0.957 for $\mathrm{PCO}_{2}$ values. In spite of a highly significant correlation, the limits of agreement between the two methods were wide for $\mathrm{PO}_{2}$. Earlobe values of $\mathrm{PO}_{2}$ were usually lower than arterial values, with larger differences in the range of normal arterial $\mathrm{PO}_{2}$. On the other hand, the error and the limits of agreement were smaller for $\mathrm{PCO}_{2}$.

We conclude that, in adult patients, arterialized earlobe blood $\mathrm{PO}_{2}$ is not a reliable mirror of arterial $\mathrm{PO}_{2}$.

Eur Respir J., 1996, 9: 186-189.

Blood gas values can be measured using arterialized earlobe blood samples, instead of arterial samples, in order to gauge pulmonary gas exchange in acute or chronically ill patients. This method, described many years ago [1], is a simple and safe procedure which can be performed by medical technicians. Comparing values for partial pressure of oxygen $\left(\mathrm{PO}_{2}\right)$ and of carbon dioxide $\left(\mathrm{PCO}_{2}\right)$ from arterialized earlobe blood samples with arterial blood samples, several authors have concluded that the earlobe site was suitable for routine clinical purposes [1-9]. This idea was again advocated by two recent studies. PitKIn et al. [10] compared $\mathrm{PO}_{2}, \mathrm{PCO}_{2}$, and pH values from 40 blood samples simultaneously drawn from the radial artery and hyperaemic earlobe. Using the method of BLAND and ALTMAN [11] for the assessment of agreement, these authors also concluded that arterialized earlobe blood gas values were accurate enough to be used in clinical application. Finally, DAR et al. [12] reported that earlobe sampling was significantly less painful than arterial sampling in 55 patients, whereas blood gas values were not different with the two techniques.

For several years, the arterialized earlobe technique has been the standard practice for measuring arterial blood gases in our pulmonary function laboratory. However, in some instances, we have noticed a marked discrepancy between arterial and relatively lower arterialized earlobe values of $\mathrm{PO}_{2}$. We, therefore, conducted a prospective study to compare arterial and arterialized earlobe blood samples in 115 consecutive adult patients.
Division de Pneumologie, Centre Hospitalier Universitaire Vaudois, Lausanne, Switzerland

Correspondence: J.W. Fitting

Division de Pneumologie

CHUV

1011 Lausanne

Switzerland

Keywords: Arterialized earlobe blood gas

Received: March 291995

Accepted after revision July 141995

\section{Material and methods}

Our study group included 115 consecutive adult patients investigated in our pulmonary function laboratory for various conditions. None was in cardiovascular shock. Blood samples were drawn simultaneously from the radial artery and the arterialized earlobe of each patient in a sitting position. A commercial capillary system with a 26-gauge needle (AVL Microsampler, Schaffhausen, Switzerland) was used to collect arterial samples. The earlobe capillary blood was arterialized by the application of a Hymenoptera venom cream (Forapin, M. Mack Nachf., Illertissen, Germany) for 5-10 min. A qualified technician then incised the earlobe at its most dependent part with a scalpel blade (surgical blade No. 11, SwanMorton, Sheffield, UK). A short manual massage was necessary in some instances. Arterialized samples were collected in heparinized glass capillaries (Clinitubes, Radiometer, Copenhagen, Denmark) and immediately introduced into the blood gas analyser (ABL 520, Radiometer, Copenhagen, Denmark) followed within 2 min by arterial samples.

\section{Statistical analysis}

The statistical analysis for assessing agreement between arterial and arterialized blood gases was performed according to Bland and Altman [11]. 


\section{Results}

No complication in the drawing of blood samples was observed with either method. The range of arterial $\mathrm{PO}_{2}$
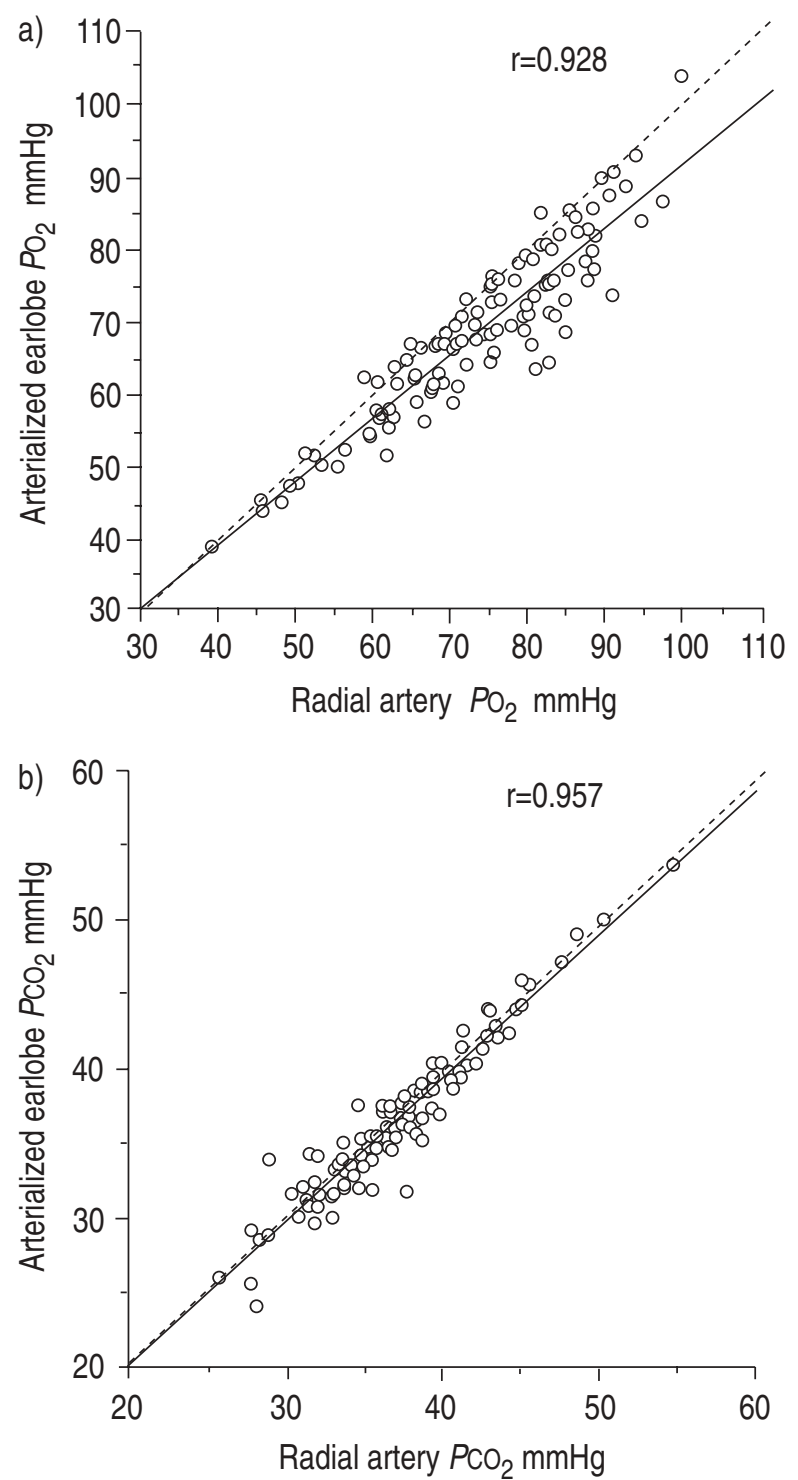

Fig. 1. - Correlation between radial artery and arterialized earlobe blood gas. a) Partial pressure of oxygen $\left(\mathrm{PO}_{2}\right)$ values; and b) partial pressure of carbon dioxide $\left(\mathrm{PCO}_{2}\right)$ values. -----.- : line of identity; : regression lines. $(1 \mathrm{mmHg}=133.32 \mathrm{~Pa})$. values was 5.2-13.1 kPa (39.0-98.3 mmHg), median 9.8 $\mathrm{kPa}(73.3 \mathrm{mmHg})$. The range of arterial $P_{\mathrm{CO}_{2}}$ values was $3.4-7.3 \mathrm{kPa}(25.7-54.6 \mathrm{mmHg})$, median $4.9 \mathrm{kPa}$ $(36.9 \mathrm{mmHg})$. The relationships between arterial and arterialized samples for $\mathrm{PO}_{2}$ and $\mathrm{PCO}_{2}$ are shown in figure $1 \mathrm{a}$ and $\mathrm{b}$. The correlation coefficients were 0.928 $(\mathrm{p}<0.0001)$ and $0.957(\mathrm{p}<0.0001)$ respectively. Despite this highly significant correlation, regression lines were slightly different from lines of identity, particularly for $P_{2}$. In figure $2 \mathrm{a}$ and $\mathrm{b}$, differences between the two

a)

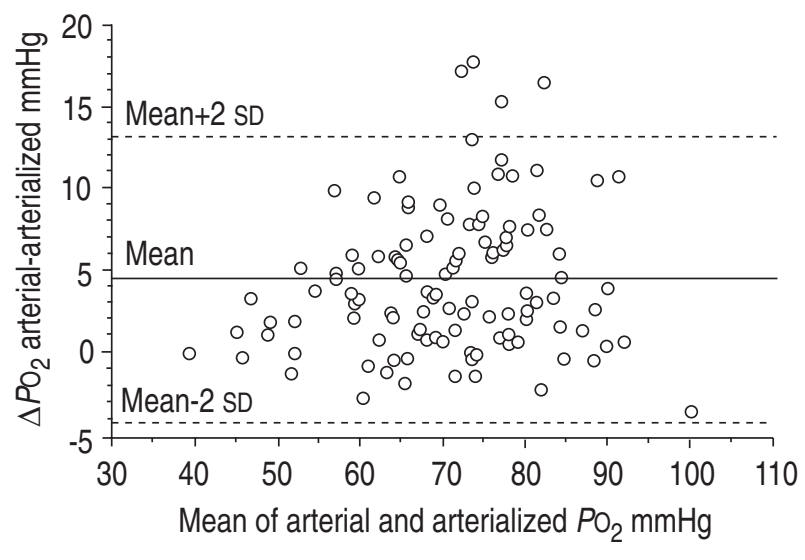

b)

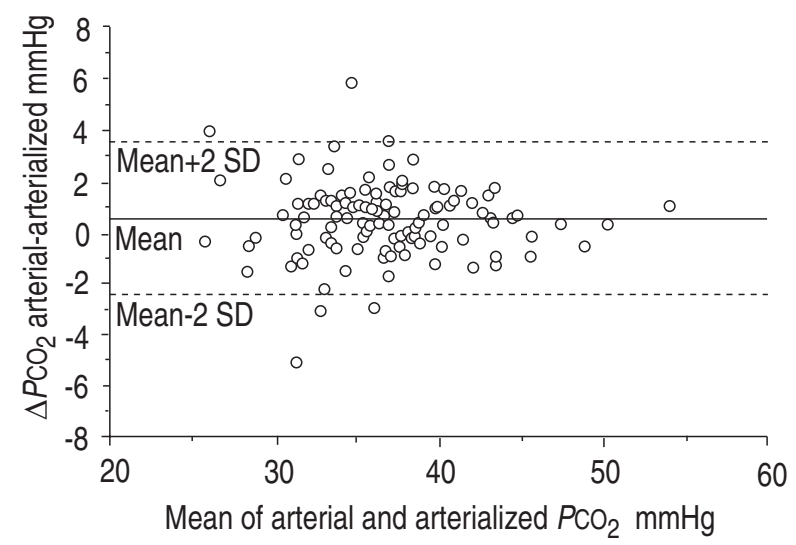

Fig. 2. - a) Differences in arterial-arterialized partial pressure of oxygen values $\left(\triangle \mathrm{PO}_{2}\right)$ plotted against mean of arterial and arterialized $\mathrm{PO}_{2}$ values. b) Differences in arterial-arterialized partial pressure of carbon dioxide $\left(\triangle \mathrm{PCO}_{2}\right)$ values plotted against mean of arterial and arterialized $\mathrm{PCO}_{2}$ values. $(1 \mathrm{mmHg}=133.32 \mathrm{~Pa})$.

Table 1. - Limits of agreement of the differences in $\mathrm{PO}_{2}$ and $\mathrm{PCO}_{2}$ values between arterial and arterialized earlobe blood samples

\begin{tabular}{lcccr}
\hline & $\mathrm{kPa}$ & $\Delta \mathrm{PO}_{2}$ & & \multicolumn{2}{c}{$\Delta \mathrm{CO}_{2}$} & $\mathrm{kPa}$ & $\mathrm{mmg}$ \\
\hline Mean \pm SD & $0.59 \pm 0.59$ & $4.4 \pm 4.4$ & $0.07 \pm 0.20$ & $0.5 \pm 1.5$ \\
Range & $-0.51-2.4$ & $-3.8-18.0$ & $-0.68-0.79$ & $-5.1-5.9$ \\
95\% CI of & $1.6-1.9$ & $11.8-14.6$ & $0.34-0.52$ & $2.9-3.9$ \\
$\quad$ mean+2 SD & $-0.4-0.77$ & $-3.0--5.8$ & $-0.25--0.37$ & $-1.9--2.8$ \\
mean-2 SD & & & & \\
\hline
\end{tabular}

$\Delta \mathrm{PO}_{2}$ : difference in partial pressure of oxygen (arterial-arterialized); $\triangle P \mathrm{CO}_{2}$ : difference in partial pressure of carbon dioxide (arterial-arterialized). 95\% CI: 95\% confidence interval. 
methods (arterial - arterialized values) were plotted against means of arterial and arterialized $\mathrm{PO}_{2}$ or $\mathrm{PCO}_{2}$. The mean \pm SD and the range of the differences, as well as the 95\% confidence intervals for the lower and upper limits of agreement are reported in table 1. Arterialized earlobe $\mathrm{PO}_{2}$ was lower than arterial $\mathrm{PO}_{2}$ in most cases, and the difference increased as arterial $P_{2}$ increased. These results show that the limits of agreement for $\mathrm{PO}_{2}$ were wide, disclosing a lack of agreement between the two methods. For $\mathrm{PCO}_{2}$, on the other hand, the mean difference between the two methods was close to zero, and the limits of agreement were narrower.

\section{Discussion}

Sampling arterialized earlobe blood has been advocated by several authors as a simple and reliable method for arterial blood gas determination. The validity of this method was supported on the basis of simple comparison [2], lack of significant difference [1, 4, 8, 12], or presence of significant correlations between arterialized earlobe and arterial blood $\mathrm{PO}_{2}$ and $\mathrm{PCO}_{2}$ [3, 5-8]. Recently, PitKIn et al. [10] addressed the same question, using the method of Bland and Altman [11] to compare blood gas values from arterialized earlobe and arterial samples. They also concluded that the earlobe method was accurate enough for clinical purposes and recommended its use in routine clinical practice [10].

Our study combines the largest number of blood gas comparisons and the use of the method of BLAND and Altman [11] to compare $\mathrm{PO}_{2}$ and $\mathrm{PCO}_{2}$ between simultaneous samples of arterialized earlobe and arterial blood. The data show that $\mathrm{PO}_{2}$ was usually lower in earlobe than in arterial blood, and that the limits of agreement were wide between the two methods. Thus, using the same method of comparison as PITKIN et al. [10], our results and our conclusion differ from theirs. The reasons are that our study included both a larger number of subjects and a larger number of $\mathrm{PO}_{2}$ values in the normal range. The main cause of underestimation of arterial $\mathrm{PO}_{2}$ in earlobe samples is insufficient arterialization of blood, corresponding to a certain venous admixture. The effect of a given venous admixture in earlobe blood depends on the arterio-venous $\mathrm{PO}_{2}$ difference: the larger the arterio-venous $\mathrm{O}_{2}$ difference, the wider the discrepancy between earlobe and arterial $P_{\mathrm{O}_{2}}$. This is one likely reason for the unreliable $\mathrm{PO}_{2}$ values measured in arterialized earlobe blood in patients breathing $100 \%$ oxygen $[4,9,13]$. Because the arterio-venous $\mathrm{PO}_{2}$ difference is large in subjects with normal arterial $\mathrm{PO}_{2}$, a small venous admixture in earlobe blood will result in a greater discrepancy between earlobe and arterial $\mathrm{PO}_{2}$.

Our data support this explanation. Indeed, figure $2 \mathrm{a}$ shows that arterial $\mathrm{PO}_{2}$, when in the normal range, was often markedly underestimated by the earlobe sample. Interestingly and despite fewer normal $\mathrm{PO}_{2}$ values, the study of PITKIN et al. [10] also showed a trend towards increased difference between arterial and arterialized $\mathrm{PO}_{2}$ with increasing mean $\mathrm{PO}_{2}$ values. Accordingly, and as reported by the same authors, we observed a better agreement between the two methods for arterial $\mathrm{PO}_{2}$ values lower than $8.0 \mathrm{kPa}(60 \mathrm{mmHg})$, where the effect of venous admixture is smaller. The similarity of data over similar ranges of $\mathrm{PO}_{2}$ argues against differences in techniques for arterializing and collecting earlobe blood between the two studies. On the other hand, there was a good agreement between earlobe and arteria values of $\mathrm{PCO}_{2}$, as previously reported [10]. This reflects the insignificant effect of venous admixture, due to the comparatively smaller arteriovenous $\mathrm{PCO}_{2}$ difference.

In a recent study performed in 55 patients, DAR et al. [12] concluded that the mean differences (arterial minus capillary) were trivial and nonsignificant for $\mathrm{PO}_{2}$ and $P_{C_{2}}$. However, their reported standard deviation for $\mathrm{PO}_{2}$ differences was the same as ours $(0.59 \mathrm{kPa},(4.4$ $\mathrm{mmHg})$ ). Thus, displaying their data according to BLAND and AltMAn [11] would probably disclose a lack of agreement between the two techniques.

The usefulness of each method should be weighed according to its advantages and inconveniences. The advocated advantages of the earlobe method are that it is safe and can be performed by nonmedical staff. However, the method is not straightforward and requires trained personnel. The poor agreement with arterial blood demonstrated in this study adds to the limitations of the method. On the other hand, radial artery puncture using a capillary kit with a thin needle is a safe procedure. In our experience, no adverse effect has been noted, and although discomfort and pain were not formally assessed, most patients stated that radial artery puncture was less painful than earlobe hyperaemia and incision. This observation is at variance with that of DAR et al. [12], who quantified the discomfort associated with each procedure and found that radial arterial puncture was significantly more painful than earlobe incision. This discrepancy may be explained by the fact that we used a thinner needle for radial arterial puncture.

In conclusion, our study indicates that arterialized earlobe blood is not suitable for clinical assessment of arterial $\mathrm{PO}_{2}$ because it often underestimates its actual value. If systematic arterial sampling is not feasible, we recommend that arterial blood be drawn whenever arterialized earlobe $\mathrm{PO}_{2}$ is below the normal range.

\section{References}

1. Langlands JHM, Wallace WFM. Small blood-samples from ear-lobe puncture: a substitute for arterial puncture. Lancet 1965; ii: 315-317.

2. Christoforides C, Miller JM. Clinical use and limitations of arterialized capillary blood for $\mathrm{PO}_{2}$ determination. Am Rev Respir Dis 1968; 98: 653-657.

3. MacIntyre J, Norman JN, Smith G. Use of capillary blood in measurement of arterial $\mathrm{PO}_{2}$. Br Med J 1968; 3: 640-643.

4. Godfrey S, Wozniak ER, Courtenay Evans RJ, Samuels CS. Ear lobe blood samples for blood gas analysis at rest and during exercise. Br J Dis Chest 1971; 65: 5864. 
5. Sadove MS, Thomason RD, Jobgen E. Capillary versus arterial blood gases. Anesth Analg 1973; 52: 724-727.

6. Davis RH, Beran AV, Galant SP. Capillary pH and blood gas determinations in asthmatic children. J Allergy Clin Immunol 1975; 56: 33-38.

7. Germouty J, Bonnaud F, Germouty C, Boyer M. Prélèvements capillaires et analyse des gaz du sang. Sem Hôp Paris 1976; 52: 377-382.

8. Spiro SG, Dowdeswell IRG. Arterialized earlobe blood samples for blood gas tensions. Br J Dis Chest 1976; 70: 263-268.

9. Gaultier C, Koch G, Helms P. Measurement of blood gases. Eur Respir J 1989; 2 (Suppl. 4): 160s-163s.
10. Pitkin AD, Roberts CM, Wedzicha JA. Arterialised earlobe blood gas analysis: an underused technique. Thorax 1994; 49: 364-366.

11. Bland JM, Altman DG. Statistical methods for assessing agreement between two methods of clinical measurement. Lancet 1986; i: 307-310.

12. Dar K, Williams T, Aitken R, Woods KL, Fletcher S. Arterial versus capillary sampling for analysing blood gas pressures. Br Med J 1995; 310: 24-25.

13. Hofford JM, Dowling AS. Value of capillary blood gas analysis in the management of acute respiratory distress (Letter). Am Rev Respir Dis 1976; 113: 707708. 